\title{
Hasil Kali Matriks (Mod 2) pada Graf Roda, Graf Pertemanan dan Graf Bunga
}

\author{
Fransiskus Fran ${ }^{1 *}$, Novita Indah Saputri² ${ }^{2}$, Mariatul Kiftiah ${ }^{3}$ \\ 1,2,3 Jurusan Matematika, Fakultas MIPA, Universitas Tanjungpura, \\ Jl. Prof. Dr. Hadari Nawawi, Kota Pontianak 78124, Kalimantan Barat, Indonesia \\ *Penulis Korespondensi. Email: fransiskusfran@math.untan.ac.id
}

\begin{abstract}
ABSTRAK
Pada artikel ini dibahas sifat-sifat hasil kali matriks $(\bmod 2)$ terkait graf roda $\left(W_{n}\right)$, graf pertemanan $\left(F_{n}\right)$ dan graf bunga $\left(F l_{n}\right)$ yang grafikal. Beberapa hasil yang diperoleh, $A\left(W_{n}\right) A\left(\overline{W_{n}}\right)(\bmod 2)$ dan $A\left(\overline{W_{n}}\right) A\left(S_{n}\right)(\bmod 2)$ grafikal apabila $n=2 k+1$, dengan $S_{n}$ merupakan graf bintang. Selanjutnya, diperoleh $A\left(W_{n}\right) A\left(G_{0}\right)(\bmod 2)$ dan $A\left(\overline{W_{n}}\right) A\left(G_{0}\right)(\bmod 2)$ grafikal untuk semua $n \geq 3$, dengan $G_{0}$ adalah subgraf dari $W_{n}$ dengan $\operatorname{deg}_{G_{0}} v_{0}=$ $0, \operatorname{deg}_{G_{0}} v_{l}=\operatorname{deg}_{W_{n}} v_{l}$, untuk $1 \leq l \leq n$. Hasil kali matriks (mod 2) yang grafikal juga diperoleh untuk graf pertemanan dan graf bunga dengan komplemen dan subgrafnya masing- masing. Hasil lebih umum diperoleh untuk kondisi sehingga $A(G) A(G)(\bmod 2)$ grafikal.
\end{abstract}

Kata Kunci:

Matriks Ketetanggaan; Subgraf; Graf Roda; Graf Pertemanan; Graf Bunga; Hasil Kali Matriks

\section{ABSTRACT}

In this paper, we discussed the properties of the wheel, flower and friendship graphs for which the matrix product under modulo 2 were graphical. Let $S_{n}$ be a star graph and $\mathrm{G}_{0}$ be a subgraph of $W_{n}$ where $\operatorname{deg}_{G_{0}} v_{0}=0, \operatorname{deg}_{G_{0}} v_{l}=\operatorname{deg}_{W_{n}} v_{l}$, for $1 \leq l \leq n$. We proved the matrix product $A\left(W_{n}\right) A\left(\overline{W_{n}}\right)(\bmod 2)$ and $A\left(\overline{W_{n}}\right) A\left(S_{n}\right)(\bmod 2)$ was graphical for $n=2 k+1$, and the matrix product $A\left(W_{n}\right) A\left(G_{0}\right)(\bmod 2)$ and $A\left(\overline{W_{n}}\right) A\left(G_{0}\right)(\bmod 2)$ was graphical for all $n \geq 3$. For the next, a graphical matrix product (mod 2) was also obtained for the friendship graph and the flower graph with its complement and subgraph, respectively. As more general results were obtained for conditions such that $A(G) A(G)(\bmod 2)$ was graphical.

\section{Keywords:}

Adjacency Matrix; Subgraph; Wheel Graph; Flower Graph; Friendship Graph; Matrix Product

Format Sitasi:

F. Fran, N. I. Saputri and M. Kiftiah, "Hasil Kali Matriks (Mod 2) pada Graf Roda, Graf Pertemanan dan Graf Bunga," Jambura J. Math., vol. 3, no. 2, pp.167-179, 2021.

\section{Pendahuluan}

Suatu graf $G$ adalah pasangan himpunan $(V, E)$ dengan $V$ merupakan himpunan tak kosong dari simpul-simpul dan $E$ merupakan himpunan (boleh kosong) pasangan simpul-simpul ( $E \subseteq V \times V)$. Pasangan simpul selanjutnya disebut sisi. Berdasarkan

e-ISSN: 2656-1344 (C) 2021 F. Fran., N. I. Saputri, M. Kiftiah | Under the license CC BY-NC 4.0

Received: 6 May 2021 | Accepted: 7 June 2021 | Online: 9 June 2021 
sisinya, graf $G$ merupakan graf sederhana jika tidak memuat loop dan sisi ganda. Pada artikel ini lebih khusus akan dibahas terkait graf sederhana. Terdapat beberapa graf sederhana yang menjadi fokus pada tulisan ini, yaitu graf roda, graf pertemanan dan graf bunga. Graf roda merupakan graf yang dapat dibentuk dari graf cycle, dan berdasarkan graf roda dapat dibentuk graf pertemanan dan graf helm. Lebih lanjut, dari graf helm dapat dibentuk graf bunga.

Berdasarkan graf sederhana yang telah dipaparkan, dapat dibentuk pula graf baru yaitu komplemen graf dan subgraf. Misalkan $G$ graf sederhana, komplemen dari $G$ dinotasikan dengan $\bar{G}$ merupakan graf dengan $V(\bar{G})=V(G)$ dan sisi $(u, v) \in E(\bar{G})$ jika dan hanya jika sisi $(u, v) \notin E(G)$. Sedangkan, $H$ merupakan subgraf dari $G$ jika dan hanya jika $V(H) \subseteq V(G)$ dan $E(H) \subseteq E(G)$.

Jika diberikan suatu graf, maka graf ini dapat direpresentasikan dalam bentuk matriks. Salah satu matriks yang dapat merepresentasikan graf adalah matriks ketetanggaan. Telah banyak penelitian terkait matriks ketetanggaan, diantaranya oleh Metha dan Acharya [1] yang meneliti tentang matriks ketetanggaan dari hasil kali graf. Pada tahun 2013, Prasad, et.al. [2] memperkenalkan tentang konsep perkalian matriks ketetanggaan dari graf-graf dengan banyak simpul yang sama, untuk memperoleh graf baru. Apabila hasil kali matriks ketetanggaan menghasilkan matriks simetris $(0,1)$ dengan diagonal nol, maka akan diperoleh realisasi hasil kali matriks ketetanggaan dalam bentuk graf.

Berdasarkan konsep perkalian matriks, beberapa hasil perkalian matriks pada graf sangat mungkin tidak memenuhi syarat untuk mempunyai realisasi dalam bentuk graf, salah satunya ketika terdapat entri hasil kali matriks yang bernilai selain nol atau satu. Prasad, et.al. [3] melanjutkan penelitiannya dengan memperkenalkan tentang hasil kali matriks (mod 2) pada graf dan memberikan sifat-sifat hasil kali matriks (mod 2) yang grafikal. Oleh karena masing-masing graf mempunyai karakteristik yang berbeda-beda, sifat-sifat khusus yang lebih spesifik dapat diperoleh juga terkait hasil kali matriks (mod 2). Penelitian pada graf yang lebih khusus, dilakukan oleh John dan Jency [4]-[5] tentang hasil kali matriks (mod 2) pada graf cycle dan graf Petersen yang masing-masing merupakan graf regular (graf dengan simpul-simpulnya berderajat sama). Pengembagan lainnya dilakukan oleh Bhat, et.al. [6] yang menurunkan konsep baru yaitu hasil kali matriks $A(G) B(G)$ yang grafikal, dengan $B(G)$ merupakan matriks insidensi $(0,1)$ dari graf $G$. Kemudian, sifat komutatif hasil kali matriks yang grafikal antara graf dan komplemennya yang diperumum dibahas oleh Bhat dan Sudhakara [7] dan penelitiannya dilanjutkan pada [8], membahas tentang sifat komutatif berdasarkan partisi himpunan simpul graf yang memenuhi sifat-sifat perfect matching.

Penelitian terkait hasil kali matriks ( $m o d 2$ ) untuk graf tak regular masih terbuka untuk dikaji. Dalam artikel ini dibahas tentang hasil kali matriks (mod 2) pada graf tak regular khususnya graf roda yang merupakan pengembangan dari hasil penelitian Saputri, et.al. [9] tentang perkalian matriks pada graf roda. Hasil kali matriks (mod 2) yang dibahas dikaitkan dengan komplemen dan subgrafnya. Selain itu, dibahas pula hasil kali matriks (mod 2) pada graf pertemanan dan graf bunga yang masih merupakan keluarga graf roda. 


\section{Dasar Teori}

Seperti yang telah dipaparkan, untuk memperoleh hasil kali matriks, terlebih dahulu perlu diketahui matriks ketetanggaan dari graf yang diberikan. Untuk itu, diberikan definisi matriks ketetanggaan sebagai berikut.

Definisi 1. [2] Misalkan $G=(V, E)$ graf sederhana dan tak berarah dengan $V(G)=$ $\left\{v_{1}, v_{2}, \cdots, v_{n}\right\}$. Matriks ketetanggaan dari $G$ dinyatakan dengan $A(G)=\left(a_{i j}\right)$ adalah matriks berukuran $n \times n$ dengan $a_{i j}=1$ jika simpul $v_{i}$ dan $v_{j}$ bertetangga, selain itu $a_{i j}=0 ; 1 \leq i, j \leq n$.

Jika terdapat sisi $(u, v)$ untuk simpul $u, v \in G$, simpul $u$ dan $v$ dikatakan bertetangga dan dinotasikan dengan $u \sim{ }_{G} v$. Berdasarkan Definisi 1 dapat diketahui bahwa pada suatu graf tak berarah $G$, jika simpul $v_{i}$ bertetangga dengan $\operatorname{simpul} v_{j}$, maka simpul $v_{j}$ bertetangga dengan simpul $v_{i}$, sehingga pada matriks ketetanggaannya $A(G)=\left(a_{i j}\right)$ entri $a_{i j}$ bernilai sama dengan entri $a_{j i}$. Oleh karena itu, $A(G)$ merupakan matriks simetris. Simpul-simpul yang saling bertetangga pada graf $G$ akan menentukan derajat dari simpul tersebut, yang pada artikel ini dinotasikan $\operatorname{deg}_{G} v, v \in G$. Derajat suatu $\operatorname{simpul} v \in G$ merupakan banyak sisi yang bersisian dengan simpul $v$ [10].

Hasil kali matriks ketetanggaan dapat merupakan matriks ketetanggaann dari suatu graf tertentu jika matriks tersebut grafikal. Konsep matriks yang grafikal diberikan pada Definisi 2 dan pada Definisi 3 terkait hasil kali matriks $(\bmod 2)$.

Definisi 2. [2] Matriks grafikal adalah matriks simetris $(0,1)$ dengan diagonalnya mempunyai entri yang semuanya nol. Untuk suatu graf $G$ dan matriks grafikal $B$ dengan $B=A(G)$, maka $G$ disebut realisasi dari $B$.

Definisi 3. [3] Graf $\Psi$ merupakan hasil kali matriks ( $\bmod 2)$ dari graf $G$ dan $H$ apabila $A(G) A(H)(\bmod 2)$ adalah grafikal dan graf $\Psi$ adalah realisasi dari $A(G) A(H)(\bmod 2)$.

Contoh 1. Diberikan graf $G$ dan graf $H$ seperti pada Gambar 1.

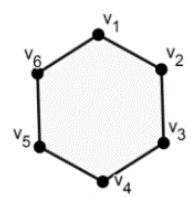

(a)

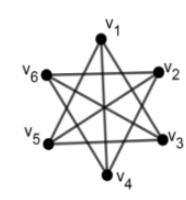

(b)

Gambar 1. (a) Graf $G$ dan (b) Graf $H$

Matriks ketetanggaan dari $G$ dan $H$ berdasarkan Definisi 1 adalah,

$$
A(G)=\left[\begin{array}{llllll}
0 & 1 & 0 & 0 & 0 & 1 \\
1 & 0 & 1 & 0 & 0 & 0 \\
0 & 1 & 0 & 1 & 0 & 0 \\
0 & 0 & 1 & 0 & 1 & 0 \\
0 & 0 & 0 & 1 & 0 & 1 \\
1 & 0 & 0 & 0 & 1 & 0
\end{array}\right] \text { dan } A(H)=\left[\begin{array}{llllll}
0 & 0 & 1 & 1 & 1 & 0 \\
0 & 0 & 0 & 1 & 1 & 1 \\
1 & 0 & 0 & 0 & 1 & 1 \\
1 & 1 & 0 & 0 & 0 & 1 \\
1 & 1 & 1 & 0 & 0 & 0 \\
0 & 1 & 1 & 1 & 0 & 0
\end{array}\right]
$$


Berdasarkan $A(G)$ dan $A(H)$ diperoleh $A(\Psi)$ yaitu hasi kali $(\bmod 2)$ dari $A(G)$ dan $A(H)$,

$$
A(\Psi)=\left[\begin{array}{llllll}
0 & 1 & 1 & 0 & 1 & 1 \\
1 & 0 & 1 & 1 & 0 & 1 \\
1 & 1 & 0 & 1 & 1 & 0 \\
0 & 1 & 1 & 0 & 1 & 1 \\
1 & 0 & 1 & 1 & 0 & 1 \\
1 & 1 & 0 & 1 & 1 & 0
\end{array}\right]
$$

Berdasarkan Definisi 2 dan Definisi 3, matriks $A(\Psi)$ grafikal, dan realisasi graf $\Psi$ seperti pada Gambar 2.

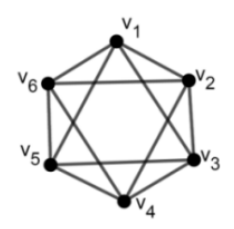

Gambar 2. Graf $\Psi$

Selanjutnya, konsep hasil kali matriks (mod 2) diterapkan untuk graf roda sebagai pengembangan dari hasil penelitian Saputri, et.al [9] dan dibahas pula untuk graf pertemanan $\left(F_{n}\right)$ yang dapat dipandang sebagai subgraf dari $\left(W_{2 n}\right)$ serta graf bunga $\left(F l_{n}\right)$ yang merupakan graf yang dibentuk dari graf helm. Untuk itu terlebih dahulu diberikan Teorema 1 yang merupakan salah satu karakteristik hasil kali (mod 2) pada suatu graf G dan komplemennya yang telah dibahas oleh Prasad, et.al [3] (untuk bukti Teorema 1 dapat dilihat di [3]).

Teorema 1. [3] Diberikan graf $G$ dengan $\bar{G}$ adalah komplemennya serta memiliki himpunan simpul yang sama yaitu $\left\{v_{0}, v_{1}, \cdots, v_{n}\right\}$. Pernyataan berikut ekuivalen:

a. $A(G) A(\bar{G})(\bmod 2)$ grafikal

b. Untuk setiap $k$ dan $l, 0 \leq k, l \leq n, \operatorname{deg}_{G} v_{k}-\operatorname{deg}_{G} v_{l} \equiv 0(\bmod 2)$

\section{Hasil dan Pembahasan}

Sebelum membahas hasil kali matriks ( $\bmod 2)$ pada graf roda, graf pertemanan dan graf bunga, diberikan definisi graf cycle, graf bintang dan masing-masing graf tersebut. Graf cycle merupakan graf sederhana yang simpul-simpulnya berderajat dua. Graf cycle dengan $n$ simpul dilambangkan dengan $C_{n}$ [11]. Graf Roda $\left(W_{n}\right)$ merupakan graf yang diperoleh dengan menambahkan satu simpul baru pada graf cycle sehingga masing-masing simpul pada graf cycle bertetangga dengan simpul baru tersebut [12]. Graf roda mempunyai himpunan simpul $V\left(W_{n}\right)=\left\{v_{l} \mid l=0,1,2, \ldots, n\right\}$ dan himpunan sisi $E\left(W_{n}\right)=\left\{\left(v_{0}, v_{l}\right),\left(v_{1}, v_{n}\right) \mid l=1,2, \ldots, n\right\} \cup\left\{\left(v_{l}, v_{l+1}\right) \mid l=1,2, \ldots, n-1\right\}$ dengan $v_{0}$ merupakan simpul pusat graf roda. Salah satu subgraf dari graf roda adalah graf bintang $\left(S_{n}\right)$ yang merupakan graf sederhana dengan 1 simpul berderajat $n$ dan $n$ simpul anting-anting (berderajat 1 ). Graf pertemanan dinotasikan $F_{n}$ adalah graf yang memiliki $n$ salinan graf $C_{3}$ yang bertemu di satu simpul pusat [13]. Graf pertemanan mempunyai $2 n+1$ simpul dan merupakan subgraf dari $W_{2 n}$. Graf pertemanan mempunyai himpunan simpul $V\left(F_{n}\right)=\left\{v_{l} \mid l=0,1,2, \ldots, 2 n\right\}$ dan himpunan sisi $E\left(F l_{n}\right)=$ $\left\{\left(v_{0}, v_{l}\right) \mid l=1,2, \ldots, 2 n\right\} \cup\left\{\left(v_{2 l-1}, v_{2 l}\right) \mid l=1,2, \ldots, n\right\}$. Dari graf roda, dapat dibentuk pula graf helm $\left(H_{n}\right)$ yaitu graf yang diperoleh dari graf roda dengan menambahkan sisi 
anting-anting pada masing-masing simpul dicycle luar [14]. Sedangkan graf bunga $\left(F l_{n}\right)$ merupakan graf yang diperoleh dari graf helm dengan menghubungkan setiap simpul anting-anting ke simpul pusat dari graf helm [14]. Graf bunga mempunyai himpunan simpul $V\left(F l_{n}\right)=\left\{v_{l} \mid l=0,1,2, \ldots, 2 n\right\}$ dan himpunan sisi $E\left(F l_{n}\right)=$ $\left\{\left(v_{0}, v_{l}\right),\left(v_{1}, v_{2 n-1}\right) \mid l=1,2, \ldots, 2 n\right\} \cup\left\{\left(v_{2 l-1}, v_{2 l}\right),\left(v_{2 l-1}, v_{2 l+1}\right) \mid l=1,2, \ldots, n\right\} . \quad$ Ilustrasi graf roda, graf pertemanan dan graf bunga dapat dilihat pada Gambar 3.

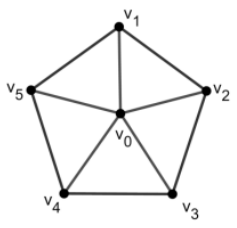

(a)

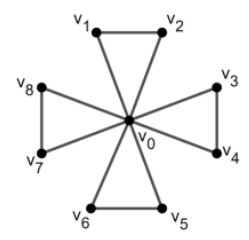

(b)

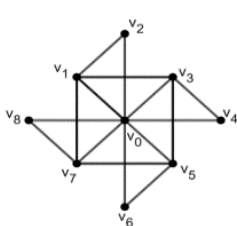

(c)

Gambar 3. (a) Graf $W_{4}$, (b) Graf $F_{4}$, (c) Graf $F_{4}$

Berdasarkan Definisi 1, $A\left(W_{n}\right)$ merupakan matriks berukuran $(n+1) \times(n+1)$. Sedangan $A\left(F_{n}\right)$ dan $A\left(F l_{n}\right)$ merupakan matriks berukuran $(2 n+1) \times(2 n+1)$. Selanjutnya, berdasarkan Definisi 2 dan Definisi 3, maka hasil kali $A\left(W_{n}\right) A\left(W_{n}\right)(\bmod 2)$ tidak grafikal, hal ini karena matriks ketetanggaan merupakan matriks simetris dan titik-titik selain titik pusat pada graf roda mempunyai derajat 3. Akibatnya, terdapat elemen diagonal utama pada matriks hasil kali tersebut yang tidak nol setelah dimodulokan 2 . Terkait perkalian matriks $(\bmod 2)$ pada graf roda dan komplemennya, diberikan pada Teorema 2.

Teorema 2. Diberikan graf roda $W_{n}$ dengan $\overline{W_{n}}$ adalah komplemennya.

a. $A\left(W_{n}\right) A\left(\overline{W_{n}}\right)(\bmod 2)$ tidak grafikal untuk $n=2 k$ dengan $k \in \mathbb{N}$ dan $k \geq 2$.

b. $A\left(W_{n}\right) A\left(\overline{W_{n}}\right)(\bmod 2)$ grafikal untuk $n=2 k+1$ dan $k \in \mathbb{N}$.

\section{Bukti:}

a. Diberikan graf $W_{n}$ dan $\overline{W_{n}}$ dengan $n=2 k$. Graf $W_{n}$ dan $\overline{W_{n}}$ memiliki himpunan simpul yang sama yaitu $\left\{v_{0}, v_{1}, v_{2}, \ldots, v_{n}\right\}$ dengan $v_{0}$ adalah simpul pusat. Akibatnya matriks ketetanggaan dari $W_{n}, A\left(W_{n}\right)=\left(a_{i j}\right)$ dengan $a_{1 j}=a_{i 1}=1,2 \leq i, j \leq n+1$ dan $a_{11}=0$, sedangkan untuk $a_{i j}$ dengan $2 \leq i, j \leq n+1$ adalah,

$$
a_{i j}=\left\{\begin{array}{lr}
1, & j=i \pm 1, j=i \pm(n-1) \\
0, & \text { lainnya. }
\end{array}\right.
$$

Matriks ketetanggaan dari $\overline{W_{n}}, A\left(\overline{W_{n}}\right)=\left(a_{i j}^{\prime}\right)$ dengan $a_{1 j}^{\prime}=a_{i 1}^{\prime}=0$, untuk $1 \leq i, j \leq$ $n+1$ dan untuk $a_{i j}^{\prime}$ dengan $2 \leq i, j \leq n+1$ adalah,

$$
a_{i j}^{\prime}=\left\{\begin{array}{lr}
0, & j=i, j=i \pm 1 \text { dan } j=i \pm(n-1) \\
1, & \text { lainnya }
\end{array}\right.
$$




\section{F. Fran, et.al.}

Dari $A\left(W_{n}\right)$ dan $A\left(\overline{W_{n}}\right)$ diperoleh $A\left(W_{n}\right) A\left(\overline{W_{n}}\right)=\left(c_{i j}\right)$ dengan entri-entriya $c_{1 j}$ untuk $2 \leq j \leq n+1$ adalah $\operatorname{deg}_{\overline{W_{n}}} v_{l} \not \equiv 0(\bmod 2)$. Sedangkan $c_{i 1}$ adalah 0 , oleh karena itu, $A\left(W_{n}\right) A\left(\overline{W_{n}}\right)$ dengan $n=2 k$ tidak grafikal.

b. Diberikan graf $W_{n}$ dan $\overline{W_{n}}$ dengan $n=2 k+1$. Untuk $n=3, \overline{W_{n}}$ merupakan graf null. Oleh karena itu, diperoleh $A\left(\overline{W_{3}}\right)$ merupakan matriks yang semua entrinya adalah nol. Akibatnya, semua entri pada $A\left(W_{3}\right) A\left(\overline{W_{3}}\right)(\bmod 2)$ adalah nol (grafikal). Untuk $n>4$ dengan $n=2 k+1, W_{n}$ dan $\overline{W_{n}}$ memiliki himpunan simpul yang sama yaitu $\left\{v_{0}, v_{1}, v_{2}, \ldots, v_{n}\right\}$ dengan $v_{0}$ adalah simpul pusat. Berdasarkan definisi graf roda $W_{n}$, diperoleh $\operatorname{deg}_{W_{n}} v_{0}=n=2 k+1$ dan $\operatorname{deg}_{W_{n}} v_{l}=3$ untuk $1 \leq l \leq n$. Akibatnya, untuk setiap $i$ dan $j, 0 \leq i, j \leq n, \operatorname{deg}_{W_{n}} v_{i}-\operatorname{deg}_{W_{n}} v_{j} \equiv 0(\bmod 2)$. Berdasarkan Teorema $1, A\left(W_{n}\right) A\left(\overline{W_{n}}\right)(\bmod 2)$ grafikal.

Contoh 2. Diberikan graf roda $W_{5}$ dan kompelmennya $\overline{W_{5}}$ seperti pada Gambar 4.

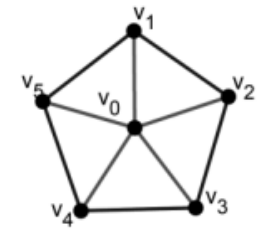

(a)

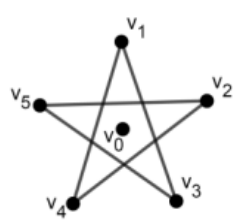

(b)

Gambar 4. (a) Graf $W_{5}$ dan (b) Graf $\overline{W_{5}}$

Dari Gambar 4, diperoleh matriks ketetanggaan $A\left(W_{5}\right)$ dan $A\left(\overline{W_{5}}\right)$ sehingga $A(\Psi)=$ $A\left(W_{5}\right) A\left(\overline{W_{5}}\right)(\bmod 2)$ adalah,

$$
A(\Psi)=\left[\begin{array}{llllll}
0 & 0 & 0 & 0 & 0 & 0 \\
0 & 0 & 1 & 1 & 1 & 1 \\
0 & 1 & 0 & 1 & 1 & 1 \\
0 & 1 & 1 & 0 & 1 & 1 \\
0 & 1 & 1 & 1 & 0 & 1 \\
0 & 1 & 1 & 1 & 1 & 0
\end{array}\right] .
$$

Berdasarkan Definisi 3, $A(\Psi)$ merupakan matriks yang grafikal, sehingga terdapat graf $\Psi$ merupakan realisasi dari $A(\Psi)$ seperti pada Gambar 5 .

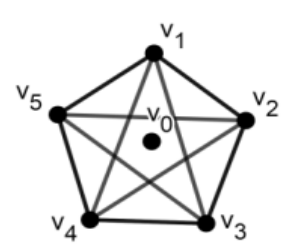

Gambar 5. Graf $\Psi$ 
Untuk selanjutnya, pembahasan berfokus pada hasil perkalian matriks $(\bmod 2)$ terkait graf roda yang grafikal.

Teorema 3. Jika diberikan graf roda $W_{n}$ dan $G_{0}$ adalah subgrafnya dengan $\operatorname{deg}_{G_{0}} v_{0}=$ $0, \operatorname{deg}_{G_{0}} v_{l}=\operatorname{deg}_{W_{n}} v_{l}$, untuk $1 \leq l \leq n$, maka $A\left(W_{n}\right) A\left(G_{0}\right)(\bmod 2)$ grafikal.

Bukti. Misalkan $W_{n}$ merupakan graf roda, $A\left(W_{n}\right)=\left(a_{i j}\right)$ sama seperti pada bukti Teorema 2 (a) dan $G_{0}$ adalah subgraf dari $W_{n}$ dengandeg $g_{G_{0}} v_{0}=0$, $\operatorname{deg}_{G_{0}} v_{l}=$ $\operatorname{deg}_{W_{n}} v_{l}$, untuk $1 \leq l \leq n$ sehingga $A\left(G_{0}\right)=\left(d_{i j}\right)$ dengan entri-entrinya $d_{1 j}=d_{i 1}=0$ untuk $1 \leq i, j \leq n+1$, dan $d_{i j}=a_{i j}$ untuk $2 \leq i, j \leq n+1$. Berdasarkan $a_{i j}$ dan $d_{i j}$ diperoleh $A\left(W_{n}\right) A\left(G_{0}\right)(\bmod 2)=\left(w_{i j}\right)$. Hasil $A\left(W_{n}\right) A\left(G_{0}\right)(\bmod 2)$ untuk $n=3,4$ merupakan matriks null (grafikal). Sedangkan untuk $n \geq 5$, diperoleh entri-entri $w_{1 j}=$ $\operatorname{deg}_{G_{0}} v_{l}=2 \equiv 0(\bmod 2), l=j-1$ dan $w_{\mathrm{i} 1}=0$ untuk $2 \leq i, j \leq n+1$. Untuk $w_{i j}$ dengan $2 \leq i, j \leq n+1$ adalah,

$$
w_{i j}=\left\{\begin{array}{rr}
1, & j=i \pm 2 \text { dan } j=i \pm(n-2) \\
0, & \text { lainnya. }
\end{array}\right.
$$

Dari $w_{i j}$ diperoleh bahwa entri diagonal pada $A\left(W_{n}\right) A\left(G_{0}\right)(\bmod 2)$ adalah 0 dan $A\left(W_{n}\right) A\left(G_{0}\right)(\bmod 2)$ merupakan matriks simetris $(0,1)$. Oleh karena itu, $A\left(W_{n}\right) A\left(G_{0}\right)(\bmod 2)$ grafikal.

Contoh 3. Diberikan graf $W_{3}$ dan $G_{0}$ seperti pada Gambar 6 .

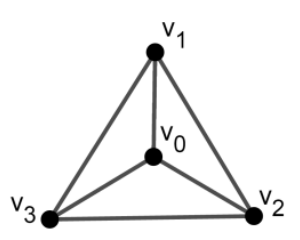

(a)

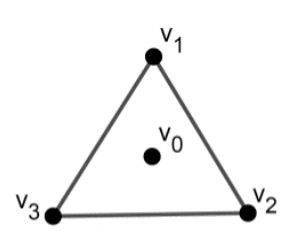

(b)

Gambar 6. (a) Graf $W_{3}$ dan (b) Graf $G_{0}$

Dari Gambar 6, hasil kali matriks ketetanggaan untuk graf $W_{3}$ dan $G_{0}$ adalah $A(\Psi)=$ $A\left(W_{3}\right) A\left(G_{0}\right)(\bmod 2)$ sebagai berikut.

$$
A(\Psi)=\left[\begin{array}{llll}
0 & 0 & 0 & 0 \\
0 & 0 & 0 & 0 \\
0 & 0 & 0 & 0 \\
0 & 0 & 0 & 0
\end{array}\right]
$$

Matriks $A(\Psi)$ adalah matriks grafikal. Oleh karena itu, $A\left(W_{3}\right) A\left(G_{0}\right)(\bmod 2)$ dapat direalisasikan dalam bentuk graf seperti pada Gambar 7. 


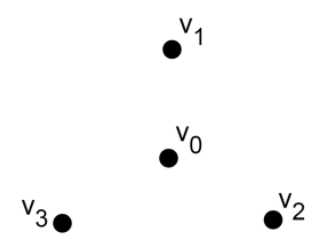

Gambar 7. Graf $\Psi$

Selanjutnya, ditinjau hasil kali matriks $(\bmod 2)$ dari komplemen graf roda dengan beberapa subgraf yang diperoleh dari graf roda. Untuk lebih jelasnya, dibahas pada Teorema 4 dan Teorema 5.

Teorema 4. Diberikan komplemen graf roda $\left(\overline{W_{n}}\right)$ dan graf bintang $S_{n}$. Jika $n=2 k+1$ dan $k \in \mathbb{N}$ maka $A\left(\overline{W_{n}}\right) A\left(S_{n}\right)(\bmod 2)$ grafikal.

Bukti. Diberikan $W_{n}$ merupakan graf roda dan $\overline{W_{n}}$ komplemen dari $W_{n}$. Seperti pada bukti Teorema 2 (a), $A\left(\overline{W_{n}}\right)=\left(a_{i j}^{\prime}\right)$ dan graf bintang $S_{n}$ (dapat dipandang sebagai subgraf $\left.W_{n}\right)$, dengan $A\left(S_{n}\right)=\left(s_{i j}\right)$ dengan $s_{1 j}=s_{i 1}=1,2 \leq i, j \leq n+1$ dan $s_{i j}=0$ untuk $i, j$ lainnya. Berdasarkan $a_{i j}^{\prime}$ dan $s_{i j}$ diperoleh $A\left(\overline{W_{n}}\right) A\left(S_{n}\right)(\bmod 2)=\left(f_{i j}\right)$. Oleh karena $\overline{W_{3}}$ merupakan graf null, $A\left(\overline{W_{3}}\right) A\left(S_{3}\right)(\bmod 2)$ merupakan matriks null (grafikal). Sedangkan untuk $n \geq 4$, entri-entri $f_{i j}$ adalah $f_{i 1}=d e g_{\overline{W_{n}}} v_{l}$, untuk $2 \leq i \leq n+1, l=$ $i-1$ dan $f_{i j}=0$ untuk $i, j$ lainnya. Oleh karena $f_{\mathrm{i} 1}=\operatorname{deg}_{\overline{W_{n}}} v_{l}$, maka agar $A\left(\overline{W_{n}}\right) A\left(S_{n}\right)(\bmod 2)$ grafikal haruslah $\operatorname{deg}_{\overline{W_{n}}} v_{l} \equiv 0(\bmod 2)$, yang dipenuhi ketika $n=$ $2 k+1, k \in \mathbb{N}$.

Contoh 4. Diberikan graf $\overline{W_{3}}$ dan graf $S_{3}$ seperti pada Gambar 8.

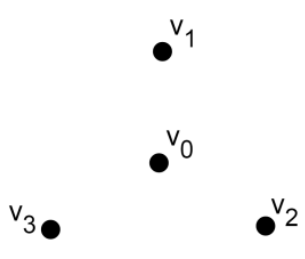

(a)

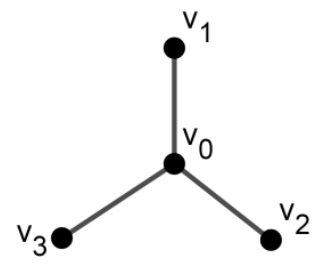

(b)

Gambar 8. (a) graf $\overline{W_{3}}$ dan (b) Graf $S_{3}$

Dari Gambar 8, dapat diperoleh matriks ketetanggaan $A\left(\overline{W_{3}}\right)$ dan $A\left(S_{3}\right)$ sehingga $A(\Psi)=A\left(\overline{W_{3}}\right) A\left(S_{3}\right)(\bmod 2)$ sebagai berikut.

$$
A(\Psi)=\left[\begin{array}{llll}
0 & 0 & 0 & 0 \\
0 & 0 & 0 & 0 \\
0 & 0 & 0 & 0 \\
0 & 0 & 0 & 0
\end{array}\right]
$$


Berdasarkan $A(\Psi)$ dapat diketahui bahwa $A\left(\overline{W_{3}}\right) A\left(S_{3}\right)(\bmod 2)$ yang grafikal. Oleh karena itu, terdapat realisasi untuk $A\left(\overline{W_{3}}\right) A(G)(\bmod 2)$ sebagai berikut.

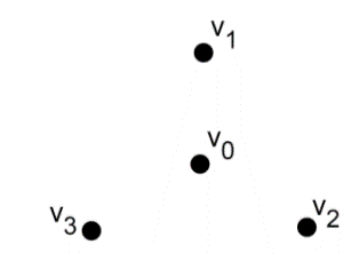

Gambar 9. Graf $\Psi$

Teorema. 5 Jika $G_{0}$ adalah subgraf dari $W_{n}$ dengan $\operatorname{deg}_{G_{0}} v_{0}=0, \operatorname{deg}_{G_{0}} v_{l}=$ $\operatorname{deg}_{W_{n}} v_{l}$, untuk $1 \leq l \leq n$, maka $A\left(\overline{W_{n}}\right) A\left(G_{0}\right)(\bmod 2)$ grafikal.

Bukti. Diberikan $W_{n}$ merupakan graf roda dan $\overline{W_{n}}$ komplemen dari $W_{n}$. Seperti pada bukti Teorema 2 (a), $A\left(\overline{W_{n}}\right)=\left(a_{i j}^{\prime}\right)$ dan graf $G_{0}$ dengan $A\left(G_{0}\right)=\left(d_{i j}\right)$ seperti pada Teorema 3. Oleh karena itu diperoleh entri-entri pada $A\left(\overline{W_{n}}\right) A\left(G_{0}\right)(\bmod 2)$ sama dengan entri-entri pada $A\left(\overline{W_{n}}\right) A\left(W_{n}\right)(\bmod 2)$ (kecuali pada kolom pertama untuk $n$ genap). Selanjutnya, berdasarkan Teorema 2, untuk $n$ ganjil, $A\left(W_{n}\right) A\left(\overline{W_{n}}\right)(\bmod 2)$ grafikal, yang berarti $A\left(\overline{W_{n}}\right) A\left(W_{n}\right)(\bmod 2)$ grafikal. Oleh karena $a_{i 1}^{\prime}=a_{1 j}^{\prime}=d_{i 1}=d_{1 j}=0,1 \leq i, j \leq n+1$, berakibat semua entri pada kolom pertama dan baris pertama dari $A\left(\overline{W_{n}}\right) A\left(G_{0}\right)(\bmod 2)$ adalah nol. Jadi, untuk ngenap, $A\left(\overline{W_{n}}\right) A\left(G_{0}\right)(\bmod 2)$ grafikal. Oleh karena itu, $A\left(\overline{W_{n}}\right) A\left(G_{0}\right)(\bmod 2)$ grafikal untuk semua $n \geq 3$.

Contoh 5. Diberikan graf $\overline{W_{4}}$ dam graf $G_{0}$ seperti pada Gambar 10.

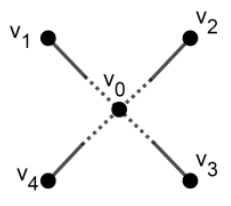

(a)

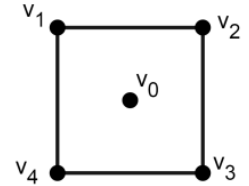

(b)

Gambar 10. (a) Graf $\overline{W_{4}}$ dan (b) Graf $G_{0}$

Dari Gambar 10, diperoleh matriks ketetanggaan $A\left(\overline{W_{4}}\right)$ dan $A\left(G_{0}\right)$ sehingga $A(\Psi)=$ $A\left(\overline{W_{4}}\right) A\left(G_{0}\right)(\bmod 2)$ adalah,

$$
A(\Psi)=\left[\begin{array}{lllll}
0 & 0 & 0 & 0 & 0 \\
0 & 0 & 1 & 0 & 1 \\
0 & 1 & 0 & 1 & 0 \\
0 & 0 & 1 & 0 & 1 \\
0 & 1 & 0 & 1 & 0
\end{array}\right]
$$

Berdasarkan $A(\Psi), A\left(\overline{W_{4}}\right) A(G)(\bmod 2)$ grafikal. Oleh karena itu terdapat realisasi $\Psi$ untuk $A\left(\overline{W_{4}}\right) A(G)(\bmod 2)$ seperti pada Gambar 11. 


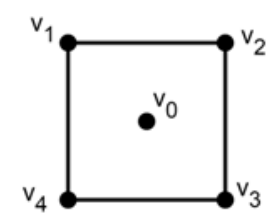

Gambar 11. Graf $\Psi$

Pada pembahasan selanjutnya, diberikan salah satu karakteristik hasil kali matriks ( $\bmod 2$ ) yang grafikal dan dinyatakan pada Teorema 6. Selain itu, dibahas pula sifatsifat hasil kali matriks $(\bmod 2)$ yang grafikal pada graf pertemanan $\left(F_{n}\right)$ dan graf bunga $\left(F l_{n}\right)$.

Teorema 6. Misalkan $G$ graf sederhana dengan $V(G)=\left\{v_{0}, v_{1}, v_{2}, \ldots, v_{n}\right\}$. Hasil kali $A(G) A(G)(\bmod 2)$ grafikal jika dan hanya jika $\operatorname{deg}_{G} v_{l} \equiv 0(\bmod 2), 0 \leq l \leq n$.

Bukti. Misalkan untuk graf sederhana $G$ dengan $V(G)=\left\{v_{0}, v_{1}, v_{2}, \ldots, v_{n}\right\}$, $A(G) A(G)(\bmod 2)$ grafikal. Artinya, jika $A(G) A(G)(\bmod 2)=\left(g_{i j}\right), 1 \leq i, j \leq n+1$, nilai $g_{i i} \equiv 0(\bmod 2)$. Disisi lain, $g_{i i}=\operatorname{deg}_{G} v_{l}, l=i-1$. Oleh karena itu, $\operatorname{deg}_{G} v_{l} \equiv$ $0(\bmod 2), 0 \leq l \leq n$. Sebaliknya, karena $A(G)$ matriks simetris, maka $A(G) A(G)(\bmod 2)$ matriks simetris $(0,1)$. Akibatnya, jika $\operatorname{deg}_{G} v_{l} \equiv 0(\bmod 2), 0 \leq l \leq n$ maka $g_{i i} \equiv 0(\bmod 2)$ yang berarti $A(G) A(G)(\bmod 2)$ grafikal.

Teorema 7. Misalkan $F_{n}$ merupakan graf pertemanan dengan $2 n+1$ simpul dan $G_{1}$ adalah subgraf dari $F_{n}$ dengan $\operatorname{deg}_{G_{1}} v_{0}=0$, $\operatorname{deg}_{G_{1}} v_{l}=\operatorname{deg}_{F_{n}} v_{l}$, untuk $1 \leq l \leq 2 n$.
a. $A\left(F_{n}\right) A\left(F_{n}\right)(\bmod 2)$ grafikal.
b. $A\left(F_{n}\right) A\left(\overline{F_{n}}\right)(\bmod 2)$ grafikal.
c. $A\left(\overline{F_{n}}\right) A\left(S_{2 n}\right)(\bmod 2)$ grafikal
d. $A\left(\overline{F_{n}}\right) A\left(G_{1}\right)(\bmod 2)$ grafikal

\section{Bukti:}

a. Berdasarkan definisi graf pertemanan $F_{n}$ dengan $V\left(F_{n}\right)=\left\{v_{0}, v_{1}, v_{2}, \ldots, v_{2 n}\right\}$, diperoleh $\operatorname{deg}_{F_{n}} v_{0}=2 n$ dan $\operatorname{deg}_{F_{n}} v_{l}=2,1 \leq l \leq 2 n$, yang berarti simpul-simpul pada $F_{n}$ mempunyai derajat genap. Akibatnya, berdasarkan Teorema 6, $A\left(F_{n}\right) A\left(F_{n}\right)(\bmod 2)$ grafikal.

b. Berdasarkan bukti pada Teorema 7 (a), simpul-simpul pada $F_{n}$ mempunyai derajat genap. Dengan demikian, untuk setiap $k$ dan $l, 0 \leq k, l \leq 2 n, \operatorname{deg}_{F_{n}} v_{k}-\operatorname{deg}_{F_{n}} v_{l} \equiv$ $0(\bmod 2)$. Akibatnya, menurut Teorema $1, A\left(F_{n}\right) A\left(\overline{F_{n}}\right)(\bmod 2)$ grafikal.

c. Diberikan graf pertemanan $F_{n}$ dengan $\overline{F_{n}}$ merupakan komplemennya, serta graf bintang $S_{2 n}$. Berdasarkan $\overline{F_{n}}$ diperoleh $A\left(\overline{F_{n}}\right)=\left(h_{i j}\right)$ dengan $h_{1 j}=h_{i 1}=0$ untuk $1 \leq i, j \leq 2 n+1$ dan graf bintang $S_{2 n}$ dengan $A\left(S_{2 n}\right)=\left(s_{i j}\right)$ seperti pada Teorema 5 untuk $1 \leq i, j \leq 2 n+1$. Berdasarkan $h_{i j}$ dan $s_{i j}$ diperoleh $A\left(\overline{F_{n}}\right) A\left(S_{2 n}\right)(\bmod 2)=$ 
$\left(m_{i j}\right)$. Akibatnya, entri-entri $m_{i j}$ adalah $m_{i 1}=\operatorname{deg}_{\overline{F_{n}}} v_{l}$, untuk $2 \leq i \leq 2 n+1, l=$ $i-1$ dan $m_{i j}=0$ untuk $i, j$ lainnya. Oleh karena $\operatorname{deg}_{\overline{F_{n}}} v_{l} \equiv 0(\bmod 2)$, maka $A\left(\overline{F_{n}}\right) A\left(S_{2 n}\right)(\bmod 2)$ grafikal.

d. Diberikan graf bunga $F_{n}$ dengan $\overline{F_{n}}$ merupakan komplemennya, serta graf $G_{1}$. Berdasarkan Teorema 7 (b) dan karena $G_{1}$ subgraf $F_{n}$ dengan $\operatorname{deg}_{G_{1}} v_{0}=$ $0, \operatorname{deg}_{G_{1}} v_{l}=\operatorname{deg}_{F_{n}} v_{l}$, untuk $1 \leq l \leq 2 n$,akibatnya, entri $A\left(G_{1}\right)=\left(p_{i j}\right)$ adalah $p_{1 j}=$ $p_{i 1}=0,1 \leq i, j \leq 2 n+1$ dan entri lainnya sama dengan entri matriks $A\left(F l_{n}\right)$. Oleh karena itu diperoleh entri-entri pada $A\left(\overline{F_{n}}\right) A\left(G_{1}\right)(\bmod 2)$ sama dengan entri-entri pada $A\left(\overline{F_{n}}\right) A\left(F_{n}\right)(\bmod 2) \quad$ dengan $A\left(\overline{F_{n}}\right) A\left(F_{n}\right)(\bmod 2)$ grafikal. Jadi, $A\left(\overline{F_{n}}\right) A\left(G_{1}\right)(\bmod 2)$ grafikal.

Teorema 8 Misalkan $F l_{n}$ merupakan graf bunga dengan $2 n+1$ simpul dan $G_{2}$ adalah subgraf $F l_{n}$ dengan $\operatorname{deg}_{G_{2}} v_{0}=0, \operatorname{deg}_{G_{2}} v_{l}=\operatorname{deg}_{F l_{n}} v_{l}$, untuk $1 \leq l \leq 2 n$.
a. $A\left(F l_{n}\right) A\left(F l_{n}\right)(\bmod 2)$ grafikal.
b. $A\left(F l_{n}\right) A\left(\overline{F l_{n}}\right)(\bmod 2)$ grafikal.
c. $A\left(\overline{F l_{n}}\right) A\left(S_{2 n}\right)(\bmod 2)$ grafikal
d. $A\left(\overline{F l_{n}}\right) A\left(G_{2}\right)(\bmod 2)$ grafikal

\section{Bukti:}

a. Berdasarkan definisi graf bunga $F l_{n}$ dengan $V\left(F l_{n}\right)=\left\{v_{0}, v_{1}, v_{2}, \ldots, v_{2 n}\right\}$, diperoleh $\operatorname{deg}_{F l_{n}} v_{0}=2 n, \operatorname{deg}_{F_{l n}} v_{l}=4, l$ ganjildan $\operatorname{deg}_{F l_{n}} v_{l}=2, l$ genap, $l \neq 0$, yang berarti simpul-simpul pada $F l_{n}$ mempunyai derajat genap. Akibatnya, berdasarkan Teorema 6, $A\left(F l_{n}\right) A\left(F l_{n}\right)(\bmod 2)$ grafikal.

b. Berdasarkan bukti pada Teorema 8 (a), simpul-simpul pada $F l_{n}$ mempunyai derajat genap. Dengan demikian, untuk setiap $k$ dan $l, 0 \leq k, l \leq 2 n, \operatorname{deg}_{F l_{n}} v_{k}-$ $\operatorname{deg}_{F l_{n}} v_{l} \equiv 0(\bmod 2) . \quad$ Akibatnya, menurut Teorema 1, $A\left(F l_{n}\right) A\left(\overline{F l_{n}}\right)(\bmod 2)$ grafikal.

c. Diberikan graf bunga $F l_{n}$ dengan $\overline{F l_{n}}$ merupakan komplemennya, serta graf bintang $S_{2 n}$. Berdasarkan $\overline{F l_{n}}$ diperoleh, $A\left(\overline{F_{l n}}\right)=\left(h^{\prime}{ }_{i j}\right)$ dengan $h_{1 j}^{\prime}=h_{i 1}^{\prime}=0,1 \leq$ $i, j \leq 2 n+1$ dan graf bintang $S_{2 n}$ dengan $A\left(S_{2 n}\right)=\left(s_{i j}\right)$ seperti pada Teorema 5 untuk $1 \leq i, j \leq 2 n+1$. Berdasarkan $h^{\prime}{ }_{i j}$ dan $s_{i j}$ diperoleh $A\left(\overline{F l_{n}}\right) A\left(S_{2 n}\right)(\bmod 2)=$ $\left(n_{i j}\right)$. Akibatnya, entri-entri $n_{i j}$ adalah $n_{i 1}=d e g_{\overline{F_{l n}}} v_{l}$, untuk $2 \leq i \leq 2 n+1, l=$ $i-1$ dan $n_{i j}=0$ untuk $i, j$ lainnya. Oleh karena $\operatorname{deg}_{\overline{F l_{n}}} v_{l} \equiv 0(\bmod 2)$, maka $A\left(\overline{F l_{n}}\right) A\left(S_{2 n}\right)(\bmod 2)$ grafikal.

d. Diberikan graf bunga $F l_{n}$ dengan $\overline{F l_{n}}$ merupakan komplemennya, serta graf $G_{2}$. Berdasarkan Teorema 8 (b) dan karena $G_{2}$ subgraf $F l_{n}$ dengan $\operatorname{deg}_{G_{2}} v_{0}=$ $0, \operatorname{deg}_{G_{2}} v_{l}=\operatorname{deg}_{F l_{n}} v_{l}$, untuk $1 \leq l \leq 2 n$. Akibatnya, entri $A\left(G_{2}\right)=\left(g_{i j}^{\prime}\right)$ adalah $g^{\prime}{ }_{1 j}=g^{\prime}{ }_{i 1}=0,1 \leq i, j \leq 2 n+1$ dan entri lainnya sama dengan entri matriks $A\left(F l_{n}\right)$. Oleh karena itu diperoleh entri-entri pada $A\left(\overline{F l_{n}}\right) A\left(G_{2}\right)(\bmod 2)$ sama 
dengan entri-entri pada $A\left(\overline{F l_{n}}\right) A\left(F l_{n}\right)(\bmod 2)$ dengan $A\left(\overline{F l_{n}}\right) A\left(F l_{n}\right)(\bmod 2)$ grafikal. Jadi, $A\left(\overline{F l_{n}}\right) A\left(G_{2}\right)(\bmod 2)$ grafikal.

\section{Kesimpulan}

Hasil kali matriks (mod 2) pada graf roda, graf pertemanan dan graf bunga yang dibahas pada artikel ini dikaitkan dengan subgraf dan komplemen masing-masing graf tersebut. Berdasarkan hasil penelitian diperoleh $A\left(W_{n}\right) A\left(\overline{W_{n}}\right)(\bmod 2)$ dan $A\left(\overline{W_{n}}\right) A\left(S_{n}\right)(\bmod 2)$ grafikal apabila $n=2 k+1, k \in \mathbb{N}$, dengan $\overline{W_{n}}$ merupakan komplemen graf roda. Selanjutnya diperoleh $A\left(W_{n}\right) A\left(G_{0}\right)(\bmod 2)$ dan $A\left(\overline{W_{n}}\right) A\left(G_{0}\right)(\bmod 2)$ grafikal untuk $n \geq 3$ dengan graf $G_{0}$ adalah subgraf dari $W_{n}$ dengan $\operatorname{deg}_{G_{0}} v_{0}=0, \operatorname{deg}_{G_{0}} v_{l}=\operatorname{deg}_{W_{n}} v_{l}$, untuk $1 \leq l \leq n$. Selain itu, untuk graf sederhan $G, A(G) A(G)(\bmod 2)$ grafikal jika dan hanya jika simpul-simpulnya $G$ mempunyai derajat genap. Hasil kali matriks (mod 2) yang grafikal juga diperoleh untuk graf pertemanan dan graf bunga dengan komplemen dan subgrafnya masingmasing yang berlaku untuk $n \geq 3$.

Berdasarkan hasil observasi untuk beberapa graf dengan simpul-simpulnya ada yang memiliki derajat ganjil dan ada yang genap, kemungkinan untuk hasil kali matriks (mod 2) adalah tidak grafikal. Namun demikian diperlukan penelitian lebih lanjut terkait hal ini. Selain itu, untuk penelitian tentang karakteristik-karakteristik graf sehingga diperoleh hasil kali matriks $(\bmod 2)$ yang grafikal masih sangat terbuka. Misalnya, terkait sifat-sifat matriks, graf-graf dengan graf pembangun yang sama, graf pohon dan lain-lain.

\section{Referensi}

[1] H.S. Mehta and U.P. Acharya, "Adjacency Matrix of Product Graphs", in International Conference on Research and Inventions in Science, Engineering $\mathcal{E}$ Technology. vol. 7, 2017, pp. 158-165.

[2] K.M. Prasad, M. Sudhakara, H.S. Sujatha, and M. Vinay. "Matrix Product of Graphs", in Combinatorial Matrix Theory and Generalized Inverses of Matrices, R. B. Bapat, S. J. Kirkland, K. M. Prasad, and S. Puntanen, Eds. India: Springer India, 2013, pp. 41-56, 2013.

[3] K.M. Prasad, M. Sudhakara, H.S. Sujatha, and K.V. Soumnya, "Matrix Product (Modulo 2) of Graphs", Indian J. Pure Appl. Math., vol. 45, no. 6, pp. 851-860, Dec. 2014, doi: 10.1007/s13226-014-0093-4.

[4] B. S. John and S. Jency, "Matrix Product (Modulo-2) Of Cycle Graphs", International Journal of Mathematics and Statistics Invention, vol. 4, no. 7, pp. 8-13, sept. 2016.

[5] B. S. John and S. Jency, "Matrix Product (Modulo-2) Of Petersen Graphs", International Journal of Mathematics Archive, vol. 7, No. 8, pp. 139-143, 2016.

[6] K. A. Bhat, K. M. Prasad, and G. Sudhakara, "Some Matrix Equestions of Graph", Advances and Applications in Discrete Mathematics, vol. 17. No. 1, pp. 2948, 2018.

[7] K. A. Bhat and G. Sudhakara, "Commuting Graph and Their Generalized Complements", Malaysian Journal of Mathematical Science, vol. 12, No.1, pp. 63-84, 
2018.

[8] K. A. Bhat and G. Sudhakara, "Commuting and Decomposition of $\mathrm{K}_{\mathrm{n}_{1}, \mathrm{n}_{2}, \cdots, \mathrm{n}_{\mathrm{k}}}$ through Realization of The Product $\mathrm{A}(\mathrm{G}) \mathrm{A}\left(\mathrm{G}_{\mathrm{k}}^{\mathrm{p}}\right)$ ", Special Issue on Linear Algebra and Its Applications (ICLAA2017), Spec. Matrices; vol. 6, pp. 343-356, 2018.

[9] N. I. Saputri, M. Kiftiah, and F. Fran, "Perkalian Matriks pada Graf Roda", Buletin Ilmiah Mat.Stat dan Terapannya (Bimaster), vol. 9, No. 2, pp. 337-342, 2020.

[10] R. Munir, Matematika Diskrit, Ed ke-3, Bandung: Informatika, 2010.

[11] H. Y. Harsya, I. H. Agustin, and D. Dafik, "Pewarnaan Titik pada Operasi Graf Sikel dengan Graf Lintasan", in Prosiding Seminar Nasional Matematika dan Pendidikan Matematika, vol. 1, 2014, pp. 11-18.

[12] N. Rahmawati and B. Rahajeng, "Dekomposisi Graf Sikel, Graf Roda, Graf Gir dan Graf Persahabatan", MATHunesa, vol. 3, np. 3, pp. 64-71, 2014.

[13] G. B. Mertzios and W. Unger, "The Friendship Problem on Graphs", in 1st International Conference on Relations, Orders and Graphs : Interaction with Computer Science (ROGICS), 2008, pp. 152-158.

[14] W. Abidin and Masni, "Pewarnaan Sisi pada Graf yang Berhubungan dengan Sikel”, Jurnal MSA, vol. 2 No. 1, pp. 69-75, 2014. 